\title{
Role of aminoglycoside-modifying enzymes and 16S rRNA methylase (ArmA) in resistance of Acinetobacter baumannii clinical isolates against aminoglycosides
}

\author{
Maryam Asadi Jouybari ${ }^{[1],[2], ~ M o h a m m a d ~ A h a n j a n ~}{ }^{[1],[2],}$ \\ Bahman Mirzaei ${ }^{[3]}$ and Hamid Reza Goli[1],[2]
}

\begin{abstract}
[1]. Mazandaran University of Medical Sciences, Faculty of Medicine, Molecular and Cell Biology Research Centre, Sari, Iran. [2]. Mazandaran University of Medical Sciences, Faculty of Medicine, Department of Medical Microbiology and Virology, Sari, Iran. [3]. Zanjan University of Medical Sciences, School of Medicine, Department of Medical Microbiology and Virology, Zanjan, Iran.
\end{abstract}

\begin{abstract}
Introduction: This study aimed to determine the role of genes encoding aminoglycoside-modifying enzymes (AMEs) and 16S rRNA methylase (ArmA) in Acinetobacter baumannii clinical isolates. Methods: We collected 100 clinical isolates of A. baumannii and identified and confirmed them using microbiological tests and assessment of the $O X A-51$ gene. Antibiotic susceptibility testing was carried out using disk agar diffusion and micro-broth dilution methods. The presence of AME genes and ArmA was detected by PCR and multiplex PCR. Results: The most and least effective antibiotics in this study were netilmicin and ciprofloxacin with $68 \%$ and $100 \%$ resistance rates, respectively. According to the minimum inhibitory concentration test, $94 \%$ of the isolates were resistant to gentamicin, tobramycin, and streptomycin, while the highest susceptibility $(20 \%)$ was observed against netilmicin. The proportion of strains harboring the aminoglycoside resistance genes was as follows: APH(3')-VIa (aphA6) (77\%), ANT(2")-Ia (aadB) (73\%), ANT(3")-Ia $(\operatorname{aadA} 1)(33 \%), A A C\left(6^{\prime}\right)-I b(a a c \mathrm{~A} 4)(33 \%), \operatorname{ArmA}(22 \%)$, and $A A C(3)-I I a(a a c \mathrm{C} 2)(19 \%)$. Among the 22 gene profiles detected in this study, the most prevalent profiles included $A P H\left(3^{\prime}\right)-V I a+A N T\left(2^{\prime \prime}\right)-I a$ (39 isolates, $100 \%$ of which were kanamycin-resistant), and $A A C(3)-I I a+A A C\left(6^{\prime}\right)-I b+A N T\left(3^{\prime \prime}\right)-I a+A P H\left(3^{\prime}\right)-V I a+A N T\left(2^{\prime \prime}\right)-I a$ (14 isolates, all of which were resistant to gentamicin, kanamycin, and streptomycin). Conclusions: High minimum inhibitory concentration of aminoglycosides in isolates with the simultaneous presence of AME- and ArmA-encoding genes indicated the importance of these genes in resistance to aminoglycosides. However, control of their spread could be effective in the treatment of infections caused by A. baumannii.
\end{abstract}

Keywords: Acinetobacter baumannii. Aminoglycoside-modifying enzymes. ArmA. Aminoglycoside resistance.

\section{INTRODUCTION}

Acinetobacter baumannii, living in the soil, the water, and different hospital environments, is an important opportunistic pathogen that causes nosocomial infections such as pneumonia, urinary tract infections, intravenous catheter-associated infections, and ventilation-associated infections, particularly in intensive care units ${ }^{1-4}$. The ability of this microorganism to remain in the hospital environment and to spread among the patients, along with their resistance to several antibiotics, are the main driving forces behind large-scale recurrent events in different countries ${ }^{5}$.

Corresponding Author: Dr. Hamid Reza Goli.

e-mail: goli59@gmail.com

(D) https://orcid.org/0000-0002-2932-1911

Received 18 August 2020

Accepted 12 November 2020
The major antibiotics used for the treatment of infections caused by this organism are beta-lactams, aminoglycosides, fluoroquinolones, and carbapenems; however, A. baumannii has shown different rates of resistance against these antimicrobial agents ${ }^{6-8}$. These infections are difficult, costly, and sometimes impossible to treat owing to the high ability of $A$. baumannii to acquire antibiotic resistance genes and the development of multidrug-resistant (MDR) strains ${ }^{9,10}$. Aminoglycosides are one of the main drugs used for the treatment of Acinetobacter infections ${ }^{11}$; however, recently, the resistance of A. baumannii to these antibiotics has also increased. Two main mechanisms of resistance to aminoglycosides are the alteration of the ribosome structure caused by mutations in the ribosomal $16 \mathrm{~S}$ rRNA and the enzymatic resistance mechanism ${ }^{12}$. The enzymatic alteration of the aminoglycoside molecule at $-\mathrm{OH}$ or $-\mathrm{NH}_{2}$ groups by 
aminoglycoside-modifying enzymes (AMEs) is the most important resistance mechanism ${ }^{12-14}$. AMEs are classified into three major groups: aminoglycoside phosphotransferase (APH), aminoglycoside acetyltransferase (AAC), aminoglycoside nucleotidyltransferase (ANT), and aminoglycoside adenylyltransferase (AAD) $)^{5,13}$. Aminoglycoside acetyltransferases cause acetylation of the $-\mathrm{NH}_{2}$ groups of aminoglycosides at the 1, 3, 2', and 6' positions using acetyl coenzyme A as a donor substrate ${ }^{15}$. Aminoglycoside phosphotransferases phosphorylate the hydroxyl groups present in the structure of aminoglycosides at the 4, 6, 9, 3', 2", 3", and 7" positions (seven different groups) with the help of ATP; the largest enzymatic group in this family is the $\mathrm{APH}\left(3^{\prime}\right)$-I group ${ }^{16}$. The proportion of strains harboring the aph $\mathrm{A} 6$ gene in A. baumannii is widespread, and this enzyme is the cause of resistance to neomycin, amikacin, kanamycin, paromomycin, ribostamycin, butirosin, and isepamicin ${ }^{17}$. Aminoglycoside nucleotidyltransferases are classified into 5 groups, and the genes encoding these enzymes can be found in chromosomes or transferred by plasmids and transposons ${ }^{12}$. These enzymes transfer an AMP group from ATP to a hydroxyl group at the 2", 3", 4', 6, and 9 positions of the aminoglycoside molecule $^{13}$. In addition to AMEs, $16 \mathrm{~S}$ rRNA methylation by the ArmA enzyme is a novel mechanism that contributes to the high level of aminoglycoside resistance in A. baumannii, as reported in the Far East, Europe, and North America ${ }^{5}$. This enzyme can be transferred by class 1 integrons and is often detected in carbapenemresistant $A$. baumannii isolates ${ }^{18}$. This study aimed to investigate the role of some important aminoglycoside-modifying enzymes and 16S rRNA methylase (ArmA) in the resistance of A. baumannii clinical isolates to aminoglycosides in Sari, located north of Iran.

\section{METHODS}

\section{Sample collection and bacterial isolates}

This study was performed on A. baumannii isolated from patients admitted to different educational hospitals in Sari, north of Iran, for 6 months (April 2019 to September 2019). The clinical specimens included blood, urine, respiratory secretions (bronchial lavage and tracheal secretions), CSF, and ulcer (surgical and burn wound). The clinical isolates were identified using conventional microbiological tests ${ }^{19}$ and confirmed by polymerase chain reaction (PCR) amplification of the blaOXA-51 gene using specific primers ${ }^{20}$; the reaction conditions are shown in Table 1.

\section{Antimicrobial susceptibility testing}

The antibiotic susceptibility pattern of the isolates was determined by the disk agar diffusion method on Muller Hinton agar (Merck, Germany) according to the Clinical and Laboratory Standards Institute (CLSI) guidelines ${ }^{21}$. The antibiotics included piperacillin $(100 \mu \mathrm{g})$, piperacillin-tazobactam $(100 / 10 \mu \mathrm{g})$, imipenem $(10 \mu \mathrm{g})$, meropenem $(10 \mu \mathrm{g})$, doripenem $(10 \mu \mathrm{g})$, ciprofloxacin $(5 \mu \mathrm{g})$, levofloxacin $(5 \mu \mathrm{g})$, trimethoprim-sulfamethoxazole $(1.25-23.75 \mu \mathrm{g})$, ceftazidime $(30 \mu \mathrm{g})$, cefotaxime $(30 \mu \mathrm{g})$, and cefepime (30 $\mu \mathrm{g})$ (MAST Co., England). The susceptibility pattern of the isolates against aminoglycosides including kanamycin, amikacin, spectinomycin, netilmicin, gentamicin, streptomycin, and tobramycin was determined using the micro-broth dilution method according to the CLSI guidelines ${ }^{21}$. For interpretation of the minimum inhibitory concentration (MIC) values, we referred to the CLSI guidelines and previous studies ${ }^{1,21,22}$. Escherichia coli ATCC 25922 and A. baumannii ATCC 19606 were used as control strains for antibiotic susceptibility testing.

\section{DNA extraction, PCR, and multiplex-PCR}

DNA was extracted from all A. baumannii isolates grown for $24 \mathrm{~h}$ using an alkaline lysis method with sodium dodecyl sulphate (SDS) and $\mathrm{NaOH}$, as previously published ${ }^{23}$, with few modifications. In brief, first, we prepared a lysis buffer by dissolving $0.5 \mathrm{~g}$ of SDS and $0.4 \mathrm{~g}$ of $\mathrm{NaOH}$ in $200 \mu \mathrm{L}$ of distilled water. Next, $4-6$ colonies of the bacteria were suspended in $60 \mu \mathrm{L}$ of lysis buffer and subsequently heated at $95{ }^{\circ} \mathrm{C}$ for $10 \mathrm{~min}$. In the next step, the suspension was centrifuged at $13000 \mathrm{rpm}$ for $5 \mathrm{~min}$, and $180 \mu \mathrm{L}$ of distilled water was added to the microtubes. The obtained supernatant was frozen at $-20^{\circ} \mathrm{C}$ until use as the extracted DNA in PCR.

Two sets of multiplex-PCR were used to detect AME-encoding genes in $A$. baumannii isolates using the specific primers shown in Table 1. APH(3')-VIa (aphA6), ANT(2")-Ia (aadB), and ArmA genes were detected in the same set; $A A C\left(6^{\prime}\right)-I b$ (aacA4) and $A A C(3)-I I a(a a c \mathrm{C} 2)$ were identified in the second set; and the ANT(3")-Ia (aadA1) gene was detected by PCR alone. The PCR and multiplex-PCR were performed in $25 \mu \mathrm{L}$ of final volume containing $12.5 \mu \mathrm{L}$ of the master mix (Ampliqon, Denmark), 10 pmol of each primer (Bioneer, South Korea), and $500 \mathrm{ng}$ of template DNA; the reaction solutions were brought to the desired volume through the addition of distilled water. The genes were amplified under standard conditions using a thermocycler machine (Bio-Rad, USA). All reactions were performed in 34 cycles, and the conditions are shown in Table 1.

\section{Statistical analysis}

The data were analyzed using SPSS (version 21). Categorical data were analyzed using the Fisher's exact test, and a P-value less than 0.05 was considered statistically significant. In addition, an independent t-test was used to examine the mean age of the subjects.

\section{RESULTS}

\section{Patients, samples, and bacterial isolates}

In this study, 100 non-duplicated $A$. baumannii clinical isolates were collected from 100 patients admitted to the teaching and educational hospitals of Sari, north of Iran. All isolates identified using the phenotypic method contained the blaOXA-51 gene according to the PCR results. The mean age of the patients was $42.08 \pm 25.08$ years (minimum age: 6 months; highest age: 88 years), and $50 \%$ of the patients were male. There was no significant difference between men and women in terms of mean age $(\mathrm{p}=0.64)$. Most of the bacterial isolates (34\%) were obtained from patients admitted to the burn wards, while $29 \%, 21 \%$, and $16 \%$ of the isolates were collected from the ICU, surgery, and pediatric wards, respectively. The most common type of specimen (73\%) for isolation of the bacteria was the wound samples; however, $15 \%$ and $12 \%$ of other clinical isolates were obtained from urine and blood cultures, respectively. 
TABLE 1: Primers used to amplify the blaOXA-51 and aminoglycoside resistance genes along with the conditions of PCR.

\begin{tabular}{|c|c|c|c|c|c|c|c|c|}
\hline Target genes & Primer sequences $\left(5^{\prime}-3^{\prime}\right)$ & 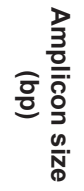 & $\begin{array}{l}\mathscr{1} \\
\stackrel{\circ}{\circ}\end{array}$ & $\begin{array}{l}\stackrel{8}{\perp} \\
\stackrel{0}{ }\end{array}$ & 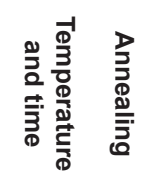 & $\begin{array}{l}\text { N } \\
\text { م̊ }\end{array}$ & $\begin{array}{l}\text { N } \\
\text { مீ}\end{array}$ & 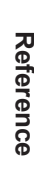 \\
\hline$O X A-51$ & $\begin{array}{l}\text { TAATGCTTTGATCGGCCTTG } \\
\text { TGGATTGCACTTCATCTTGG }\end{array}$ & 353 & $2 \min$ & $25 \mathrm{sec}$ & $\begin{array}{c}51^{\circ} \mathrm{C} \text { for } 30 \\
\text { sec }\end{array}$ & $30 \mathrm{sec}$ & $\begin{array}{c}5 \\
\min \end{array}$ & 5 \\
\hline $\begin{array}{c}A P H\left(3^{\prime}\right)-V l a \\
(a p h A 6)\end{array}$ & $\begin{array}{l}\text { CGGAAACAGCGTTTTAAGA } \\
\text { TTCCTTTTGTCAGGTC }\end{array}$ & 717 & $2 \min$ & $25 \mathrm{sec}$ & $\begin{array}{c}49^{\circ} \mathrm{C} \text { for } 30 \\
\text { sec }\end{array}$ & $30 \mathrm{sec}$ & $\begin{array}{c}5 \\
\min \end{array}$ & 5 \\
\hline $\begin{array}{l}A A C(3)-1 / a \\
(\operatorname{aacC2})\end{array}$ & $\begin{array}{l}\text { ATGCATACGCGGAAGGC } \\
\text { TGCTGGCACGATCGGAG }\end{array}$ & 822 & $2 \min$ & $25 \mathrm{sec}$ & $\begin{array}{c}54^{\circ} \mathrm{C} \text { for } 30 \\
\text { sec }\end{array}$ & $30 \mathrm{sec}$ & $\begin{array}{c}5 \\
\min \end{array}$ & 5 \\
\hline $\begin{array}{l}A A C\left(6^{\prime}\right)-I b \\
(\text { aacA4) }\end{array}$ & $\begin{array}{l}\text { TATGAGTGGCTAAATCGAT } \\
\text { CCCGCTTTCTCGTAGCA }\end{array}$ & 395 & $2 \min$ & $25 \mathrm{sec}$ & $\begin{array}{l}54^{\circ} \mathrm{C} \text { for } 30 \\
\text { sec }\end{array}$ & $30 \mathrm{sec}$ & $\begin{array}{c}5 \\
\min \end{array}$ & 5 \\
\hline $\begin{array}{l}A N T(2 ")-l a \\
(a a d B)\end{array}$ & $\begin{array}{l}\text { ATCTGCCGCTCTGGAT } \\
\text { CGAGCCTGTAGGACT }\end{array}$ & 405 & $2 \min$ & $25 \mathrm{sec}$ & $\begin{array}{l}49^{\circ} \mathrm{C} \text { for } 30 \\
\text { sec }\end{array}$ & $30 \mathrm{sec}$ & $\begin{array}{c}5 \\
\min \end{array}$ & 5 \\
\hline $\begin{array}{l}\text { ANT(3")-la } \\
\text { (aadA1) }\end{array}$ & $\begin{array}{l}\text { ATGAGGGAAGCGGTGATCG } \\
\text { TTATTTGCCGACTACCTTGGT }\end{array}$ & 792 & $2 \min$ & $25 \mathrm{sec}$ & $\begin{array}{l}62{ }^{\circ} \mathrm{C} \text { for } 30 \\
\text { sec }\end{array}$ & $30 \mathrm{sec}$ & $\begin{array}{c}5 \\
\min \end{array}$ & 5 \\
\hline ArmA & $\begin{array}{l}\text { ATTCTGCCTATCCTAATTGG } \\
\text { ACCTATACTTTATCGTCGTC }\end{array}$ & 315 & $2 \min$ & $25 \mathrm{sec}$ & $\begin{array}{l}49^{\circ} \mathrm{C} \text { for } 30 \\
\text { sec }\end{array}$ & $30 \mathrm{sec}$ & $\begin{array}{c}5 \\
\min \end{array}$ & 5 \\
\hline
\end{tabular}

\section{Antimicrobial susceptibility pattern}

According to the results of the disk agar diffusion method, the most and least effective antibiotics in the present study were imipenem and ciprofloxacin, with resistance rates of $75 \%$ and $100 \%$, respectively (Table 2). Moreover, $94 \%$ of the isolates were detected as multi-drug resistant (MDR), and the most MDR isolates were collected from wound samples. Table 2 presents the antibiotic resistance patterns of all A. baumannii clinical isolates in this study based on hospital wards, as well as sample types. Resistance to the tested antibiotics was not significantly correlated with the sample types and hospital wards where the samples were collected.

Moreover, according to the MIC results, the resistance rate against gentamicin, kanamycin, tobramycin, and streptomycin was $94 \%$, while the highest susceptibility (20\%) of A. baumannii isolates was observed against netilmicin. In contrast, $74 \%, 68 \%$, and $78 \%$ of our clinical isolates were resistant to amikacin, netilmicin, and spectinomycin, respectively. The MIC ranges of aminoglycosides and their relationship with the presence of AMEs-encoding genes are shown in Table 3.

\section{Gene profiles of the isolates}

The frequency of each aminoglycoside resistance gene and its relation with the MIC ranges are shown in Table 3. In total, the proportions of aminoglycoside resistance genes among our clinical isolates of $A$. baumannii were as follows: $A P H\left(3^{\prime}\right)-V I a(a p h \mathrm{~A} 6)$ (77\%), ANT(2")-Ia (aadB) (73\%), ANT(3")-Ia (aadA1) (33\%), $A A C\left(6^{\prime}\right)-I b(a a c \mathrm{~A} 4)(33 \%), A A C(3)-I I a(a a c \mathrm{C} 2)(19 \%)$, and ArmA
(22\%). The relationship between the presence of aminoglycoside resistance genes and the aminoglycoside susceptibility pattern of the isolates is shown in Table 4. There was a significant association between the presence of all resistance genes and the non-susceptibility (resistance or intermediate resistance) to all aminoglycosides, except armA and resistance to netilmicin. Important data from this table indicates that in some groups, such as gentamicin- and tobramycin-resistant groups, all resistant isolates contained some AMEs-encoding genes such as aacC2, $a a c A 4$, and aadA1.

In addition, we detected 22 gene profiles among all clinical isolates of $A$. baumannii (Table 5). The most prevalent combination gene profiles in the present study included: 1) $A P H\left(3^{\prime}\right)-V I a+$ $A N T\left(2^{\prime \prime}\right)$-I $a$ with 39 isolates containing these genes, among which $100 \%$ isolates were resistant towards kanamycin, while almost 95\% were resistant against netilmicin and $97.4 \%$ were resistant to tobramycin and gentamicin, and 2) $A A C(3)-I I a+A A C\left(6^{\prime}\right)-$ $I b+A N T\left(3^{\prime \prime}\right)-I a+A P H\left(3^{\prime}\right)-V I a+A N T\left(2^{\prime \prime}\right)-I a$ with 14 isolates, among which $100 \%$ were resistant to gentamicin, kanamycin, and streptomycin, while almost $93 \%$ were resistant against tobramycin and spectinomycin. However, 15 isolates showed an AME gene profile with one AME gene, most of which were resistant to tested aminoglycosides. Other AME-encoding gene profiles were detected at a low rate (Table 5). However, 15, 52, 12, 5, 14, and 2 isolates in the present study contained $1,2,3,4,5$, and 6 AME genes, respectively. The most prevalent gene profiles exhibited the simultaneous presence of 2 genes followed by 5 genes and 3 AME genes. 
TABLE 2: Antimicrobial susceptibility pattern of the Acinetobacter baumannii clinical isolates in disk agar diffusion method.

\begin{tabular}{|c|c|c|c|c|c|c|c|c|c|c|c|}
\hline \multirow[b]{3}{*}{ 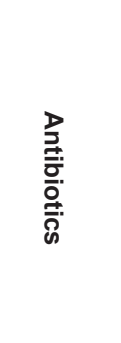 } & \multicolumn{11}{|c|}{ No. (\%) of resistant, intermediate resistant or susceptible isolates in terms of } \\
\hline & \multirow[b]{2}{*}{ 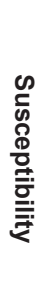 } & \multirow[b]{2}{*}{ 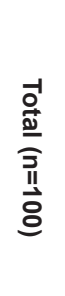 } & \multicolumn{5}{|c|}{ Hospital wards } & \multicolumn{4}{|c|}{ Sample types } \\
\hline & & & 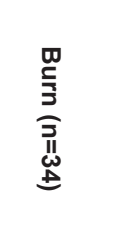 & 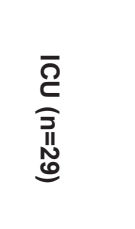 & 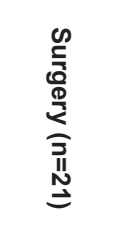 & 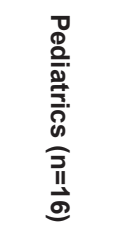 & ס & 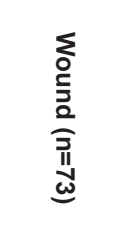 & 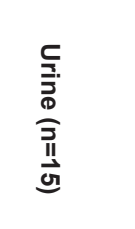 & 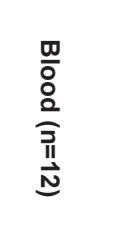 & 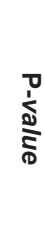 \\
\hline \multirow{3}{*}{ PIP } & $\mathrm{R}$ & 86 & $28(82.3)$ & $28(96.5)$ & $19(90.4)$ & $11(68.7)$ & \multirow{3}{*}{ 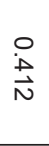 } & $62(84.9)$ & $14(93.3)$ & $10(83.3)$ & \multirow{3}{*}{$\begin{array}{l}\stackrel{\circ}{\varphi} \\
\stackrel{\varphi}{V}\end{array}$} \\
\hline & I & 10 & $5(14.7)$ & $1(3.4)$ & $2(9.5)$ & $2(12.5)$ & & $8(10.9)$ & $1(6.6)$ & $1(8.3)$ & \\
\hline & S & 4 & $1(2.9)$ & 0 & 0 & $3(18.7)$ & & $3(4.1)$ & 0 & $1(8.3)$ & \\
\hline \multirow{3}{*}{ PIP-TAZ } & $\mathrm{R}$ & 78 & $26(76.4)$ & $24(82.7)$ & $16(76.1)$ & $12(75)$ & \multirow{3}{*}{$\begin{array}{l}\stackrel{\circ}{\vec{\circ}} \\
\stackrel{+}{1}\end{array}$} & $54(73.9)$ & $14(93.3)$ & $10(83.3)$ & \multirow{3}{*}{ o } \\
\hline & 1 & 10 & $4(11.7)$ & $2(6.8)$ & $3(14.2)$ & $1(6.2)$ & & $8(10.9)$ & 0 & 2 (16.6) & \\
\hline & $S$ & 12 & $4(11.7)$ & $3(10.3)$ & $2(9.5)$ & $3(18.7)$ & & $11(15)$ & $1(6.6)$ & 0 & \\
\hline \multirow{3}{*}{ CAZ } & $\mathrm{R}$ & 76 & 25 (73.5) & $22(75.8)$ & $18(85.7)$ & $11(68.7)$ & \multirow{3}{*}{ 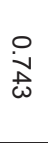 } & $52(71.2)$ & $15(100)$ & $9(75)$ & \multirow{3}{*}{$\begin{array}{l}\text { ㅇ } \\
\text { Uू }\end{array}$} \\
\hline & 1 & 0 & 0 & 0 & 0 & 0 & & 0 & 0 & 0 & \\
\hline & $S$ & 24 & $9(26.4)$ & $1(3.4)$ & $3(14.2)$ & $5(31.2)$ & & $21(28.7)$ & 0 & $3(25)$ & \\
\hline \multirow{3}{*}{ CTX } & $\mathrm{R}$ & 93 & $32(94.1)$ & $28(96.5)$ & $19(90.4)$ & $14(87.5)$ & \multirow{3}{*}{$\begin{array}{l}\stackrel{\circ}{N} \\
\text { गี }\end{array}$} & 67 (91.7) & $15(100)$ & 11 (91.6) & \multirow{3}{*}{ 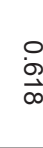 } \\
\hline & 1 & 0 & $2(5.8)$ & $1(3.4)$ & $2(9.5)$ & $2(12.5)$ & & $6(8.2)$ & 0 & $1(8.3)$ & \\
\hline & $S$ & 7 & 0 & 0 & 0 & 0 & & 0 & 0 & 0 & \\
\hline \multirow{3}{*}{ CEF } & $\mathrm{R}$ & 92 & $32(94.1)$ & $28(96.5)$ & $18(85.7)$ & 14 (87.5) & \multirow{3}{*}{$\stackrel{\circ}{\stackrel{+}{+}}$} & 67 (91.7) & $14(93.3)$ & 11 (91.6) & \multirow{3}{*}{$\stackrel{\text { N }}{\text { N }}$} \\
\hline & 1 & 4 & $1(2.9)$ & $1(3.4)$ & $2(9.5)$ & 0 & & $2(2.7)$ & $1(6.6)$ & $1(8.3)$ & \\
\hline & $S$ & 4 & $1(2.9)$ & 0 & $1(4.7)$ & $2(12.5)$ & & $4(5.4)$ & 0 & 0 & \\
\hline \multirow{3}{*}{ IMI } & $\mathrm{R}$ & 75 & $27(79.4)$ & $25(86.2)$ & 17 (80.9) & $10(62.5)$ & \multirow{3}{*}{$\begin{array}{l}\stackrel{\circ}{\sigma} \\
\stackrel{\vec{v}}{\vec{V}}\end{array}$} & $55(75.3)$ & $12(80)$ & $8(66.6)$ & \multirow{3}{*}{$\begin{array}{l}\circ \\
\infty \\
\omega \\
\infty\end{array}$} \\
\hline & 1 & 11 & $4(11.7)$ & $2(6.8)$ & $2(9.5)$ & $3(18.7)$ & & $9(12.3)$ & $1(6.6)$ & $1(8.3)$ & \\
\hline & $S$ & 14 & 7 (20.5) & $2(6.8)$ & $2(9.5)$ & $3(18.7)$ & & $9(12.3)$ & $2(13.3)$ & $3(25)$ & \\
\hline \multirow{3}{*}{ MER } & $\mathrm{R}$ & 97 & $33(97)$ & $28(96.5)$ & $20(95.2)$ & $16(100)$ & & $70(95.8)$ & $15(100)$ & 12 100) & \\
\hline & 1 & 0 & 0 & 0 & 0 & 0 & \% & 0 & 0 & 0 & ') \\
\hline & $S$ & 3 & $1(2.9)$ & $1(3.4)$ & $1(4.7)$ & 0 & & $3(4.1)$ & 0 & 0 & \\
\hline & $\mathrm{R}$ & 96 & $32(94.1)$ & $28(96.5)$ & $20(95.2)$ & $16(100)$ & & $69(94.5)$ & $15(100)$ & $12(100)$ & \\
\hline DOR & 1 & 2 & $1(2.9)$ & $1(3.4)$ & 0 & 0 & ฮै & $2(2.7)$ & 0 & 0 & $\dot{0}$ \\
\hline & $S$ & 2 & $1(2.9)$ & 0 & 1 (5) & 0 & & $2(2.7)$ & 0 & 0 & \\
\hline & $\mathrm{R}$ & 100 & $34(100)$ & $29(100)$ & $21(100)$ & $16(100)$ & & $73(100)$ & $15(100)$ & $12(100)$ & \\
\hline $\mathrm{CIP}$ & 1 & 0 & 0 & 0 & 0 & 0 & $\overrightarrow{\mathrm{o}}$ & 0 & 0 & 0 & $\overrightarrow{\vec{o}}$ \\
\hline & $S$ & 0 & 0 & 0 & 0 & 0 & & 0 & 0 & 0 & \\
\hline & $\mathrm{R}$ & 93 & $31(91.1)$ & $27(93.1)$ & $20(95.2)$ & 15 (93.7) & & 67 (91.7) & 14 (93.3) & $12(100)$ & \\
\hline LEV & 1 & 3 & $2(5.8)$ & 0 & 0 & $1(6.2)$ & N & $3(4.1)$ & 0 & 0 & $\frac{\infty}{N}$ \\
\hline & $S$ & 4 & $1(2.9)$ & $2(6.8)$ & $1(4.7)$ & 0 & & $3(4.1)$ & $1(6.6)$ & 0 & \\
\hline & $\mathrm{R}$ & 92 & 31 (91.1) & 27 (93.1) & $18(85.7)$ & $16(100)$ & & $68(93.1)$ & $12(80)$ & $12(100)$ & \\
\hline SXT & 1 & 3 & $1(2.9)$ & $1(3.4)$ & $1(4.7)$ & 0 & $\begin{array}{l}\dot{\omega} \\
\omega \\
\omega\end{array}$ & $1(1.3)$ & 2 (13.3) & 0 & $\stackrel{\sim}{a}$ \\
\hline & $S$ & 5 & $2(5.8)$ & $1(3.4)$ & $2(9.5)$ & 0 & & $4(5.4)$ & $1(6.6)$ & 0 & \\
\hline
\end{tabular}

PIP: piperacillin; PIP-TAZ: piperacillin-tazobactam; CAZ, ceftazidime; CTX, cefotaxime; CEF, cefepime; IMI, imipenem; MER, meropenem; DOR, doripenem; CIP, ciprofloxacin; LEV, levofloxacin; SXT, trimethoprim-sulfamethoxazole; R: resistant; I: intermediate resistant; and S: susceptible. 
TABLE 3: Aminoglycoside resistance pattern of the Acinetobacter baumannii clinical isolates in this study.

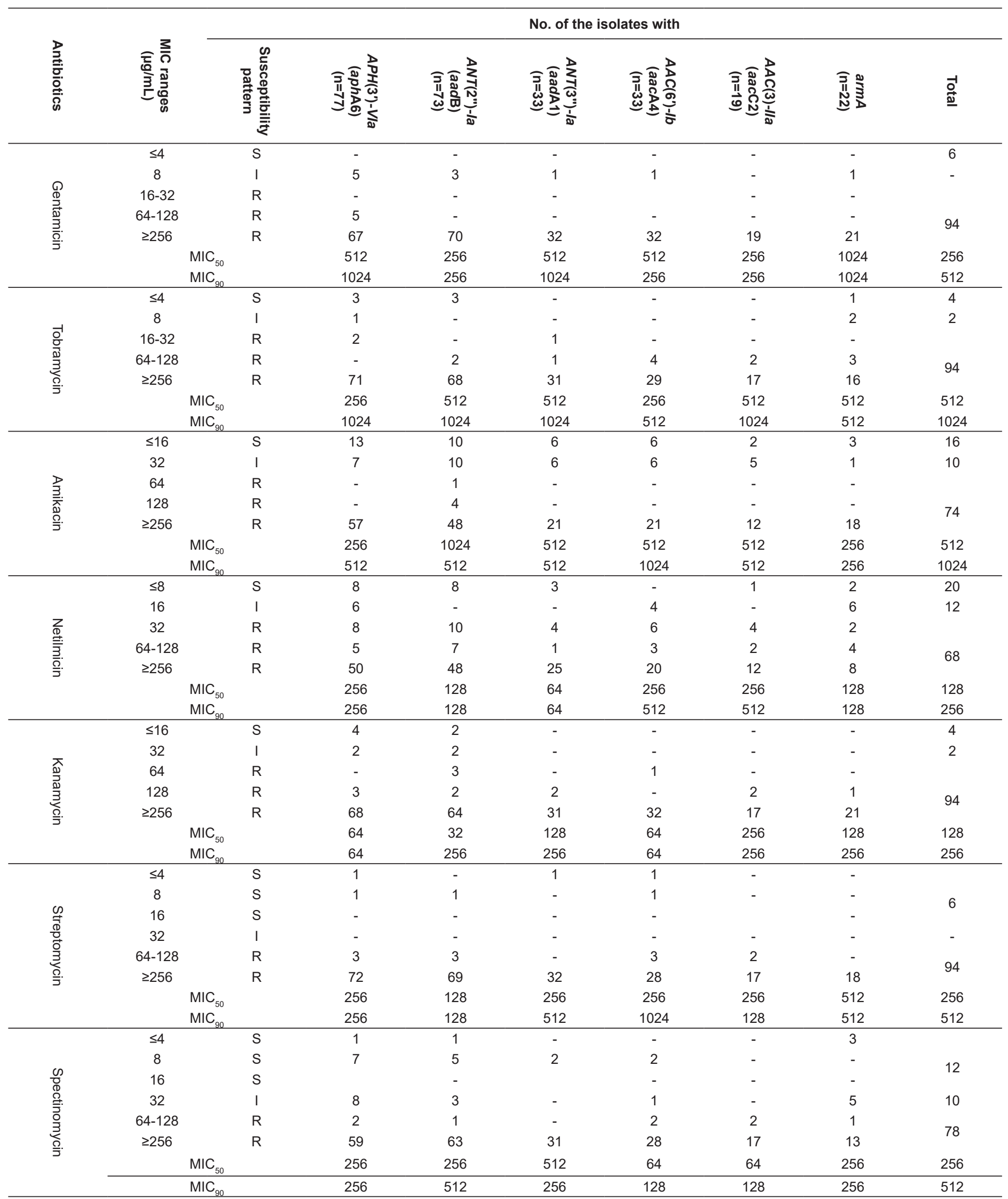

R: resistant; I: intermediate resistant; S: susceptible.

Notes: MIC : Minimum inhibitory concentration required to inhibit the growth of $50 \%$ of organisms; MIC $_{90:}$ Minimum inhibitory concentration required to inhibit the growth of $90 \%$ of organisms. 
TABLE 4: The relationship between the presence of aminoglycoside resistance genes and the aminoglycoside susceptibility pattern of the $A$. baumannii clinical isolates.

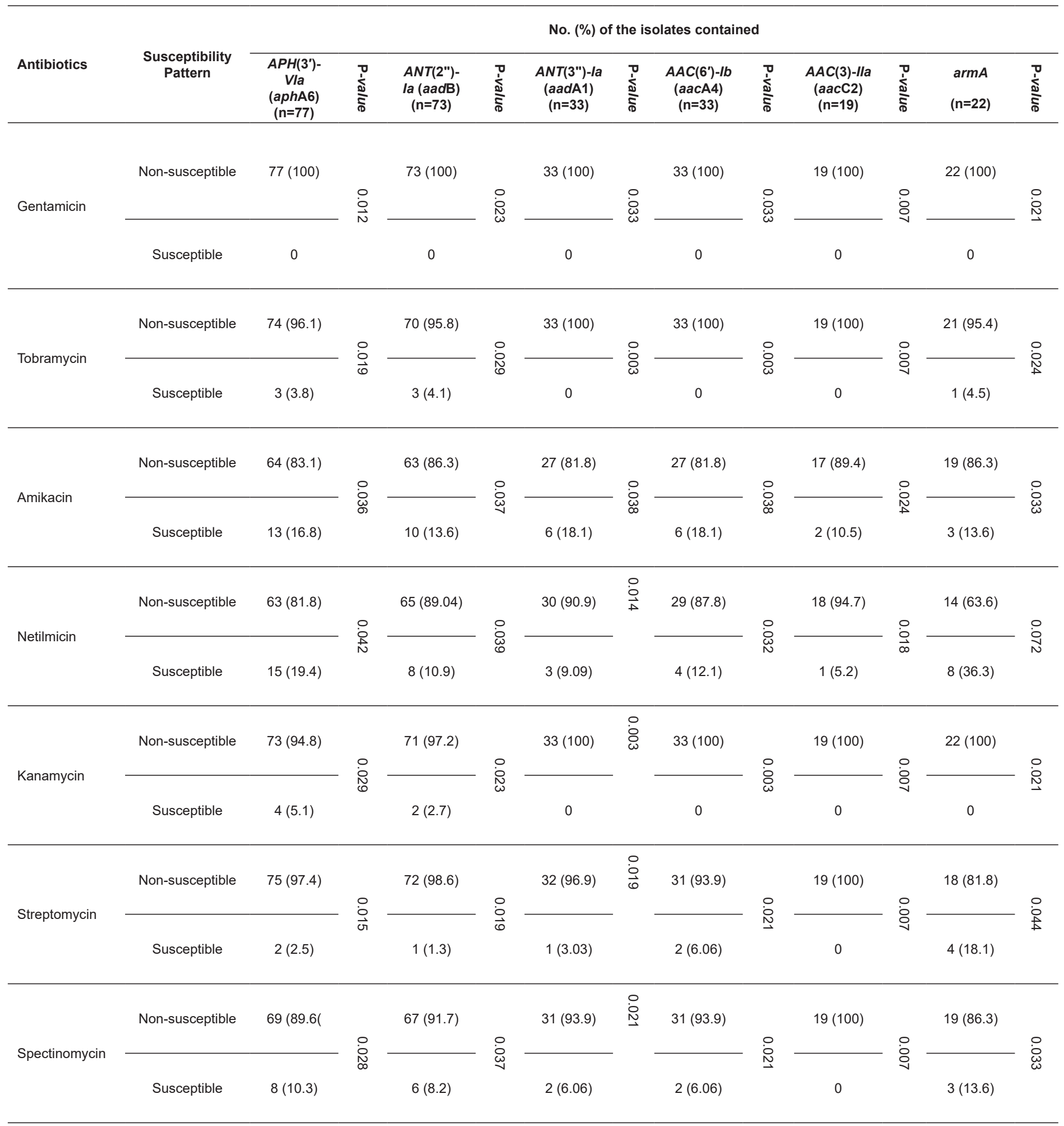




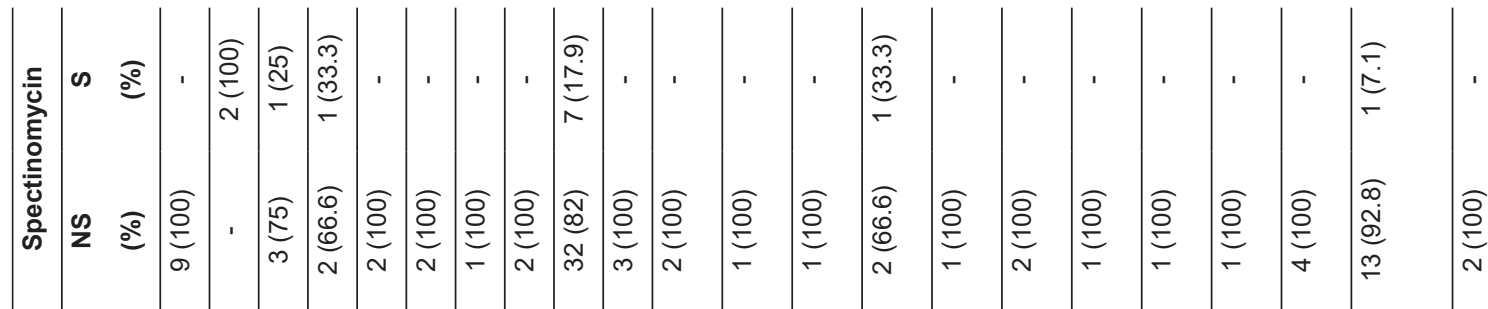

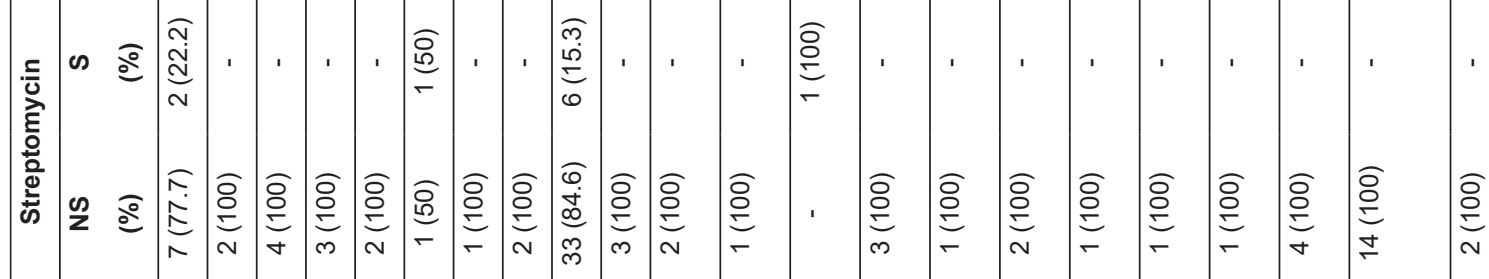

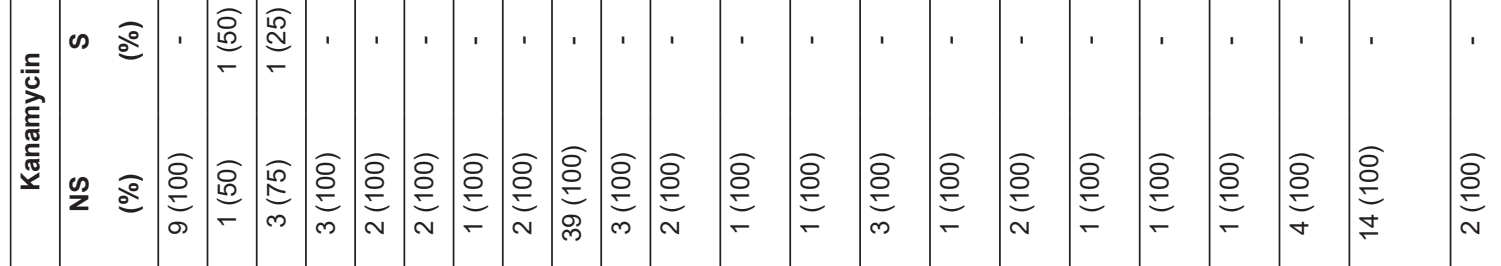




\section{DISCUSSION}

Overuse and misuse of antibiotics in the treatment of infections caused by $A$. baumannii has led to the emergence of MDR isolates in hospitals and health centers ${ }^{24}$. The spread of AME-encoding genes among the clinical isolates of $A$. baumannii is an important concern in the prescription of these traditional and effective antibiotics, as $94 \%$ of our isolates were resistant to kanamycin, gentamicin, streptomycin, and tobramycin. However, we found that netilmicin was the most effective aminoglycoside, as this antibiotic is not commonly used in the treatment of bacterial infections. This finding was similar to that of another Iranian study ${ }^{1}$. However, their isolates revealed an $\mathrm{MIC}_{50} \leq 8 \mu \mathrm{g} / \mathrm{mL}$, while in the present study it ranged from $128 \mu \mathrm{g} / \mathrm{mL}$, indicating an increased resistance rate in our region. However, the MIC ranges of other clinically important aminoglycosides such as amikacin, gentamicin, and tobramycin in the present study were significantly higher than those reported in previous studies in Iran and other countries ${ }^{1,5,25}$, while these ranges were almost similar to those reported by Yoo Jin Cho et al. in $2009^{22}$.

The molecular analysis of AME-encoding genes in the present study showed a high frequency of aphA6, $\operatorname{aadB}, \operatorname{aad} A 1, \operatorname{aac} A 4$, aac $C 2$, and $\operatorname{arm} A$ genes, consistent with the previous studies from $\operatorname{Iran}^{1,5}$. Given that AME-encoding genes can spread by transferable genetic elements $^{18}$, this high proportion would be justified. Possibly, these resistance genes can spread between different gram-negative bacteria such as Pseudomonas aeruginosa and Enterobacteriaceae. Further confirmation of this hypothesis can be found in another study conducted in Iran on the clinical isolates of $P$. aeruginos $a$, according to which $a a d B$ and $a a c A 4$ were the most prevalent AME genes ${ }^{26}$. In a study performed by Lee et al. in Korea, the highest frequency was reported for aphA6 (71\%), aacC1 (56\%), and $\operatorname{aadB}(48 \%)^{27}$.

In addition, a high proportion of $a p h A 6$ and $a a d B$ was reported by Akers et al. in USA in agreement with the present study; almost $42 \%$ of their isolates were collected from the burn ward and ICU. However, the resistance rates toward gentamicin and amikacin in their isolates were $96.6 \%$ and $57.1 \%$, respectively ${ }^{25}$. However, aphA6 confers resistance to amikacin and kanamycin ${ }^{17}$. Interestingly, $74 \%$ and $88.3 \%$ of our isolates containing aphA6 exhibited MIC values of $\geq 256 \mu \mathrm{g} / \mathrm{mL}$ for amikacin and kanamycin, respectively. Moreover, a study carried out in Poland revealed that aphA6 was the second most prevalent AME gene (78.7\%) among 61 A. baumannii isolates ${ }^{28}$. However, $a a d B$, the second most prevalent AME gene in the current study, confers resistance to gentamicin, tobramycin, and kanamycin in gram-negative bacteria ${ }^{26}$, while $95.8 \%, 93.1 \%$, and $87.6 \%$ of our isolates containing $a a d B$ showed an MIC range of $\geq 256 \mu \mathrm{g} / \mathrm{mL}$ for these antibiotics, respectively.

In addition, we found that $33 \%$ of our isolates contained the aacA4 gene. Other research performed in the USA detected only one isolate carrying this gene from blood and wound infections that were resistant to gentamicin, tobramycin, and amikacin ${ }^{25}$. However, $96.9 \%$ of our $a a d B$-positive isolates showed a $\geq 256 \mu \mathrm{g} / \mathrm{mL}$ MIC range for gentamicin and kanamycin; $87.8 \%$ of the isolates exhibited this MIC range for tobramycin, while in a previous study in Iran, this percentage was $26.4 \%{ }^{5}$. It is noteworthy that this gene was reported as the second most prevalent AME gene carryied by class 1 integrons among clinical isolates of $P$. aeruginosa in $\operatorname{Iran}^{26}$. However, $83.6 \%$ of the aminoglycoside-resistant $A$. baumannii isolates in South Korea contained the aacA4 gene, while their MIC ranges were 64 to greater than $1024 \mu \mathrm{g} / \mathrm{mL}^{22}$. Sheikhalizadeh et al. reported that $27.6 \%$ isolated exhibited the aadA1 gene proportion, which was almost concordant with the results of the present study 5 , while another Iranian study detected $26.4 \%$, 31\%, and $54.5 \%$ exhibiting this gene among the sequence group (SG) of $A$. baumannii, 1, 2, and 3, respectively. Any isolates belonging to SG4-9 contained this resistance gene ${ }^{1}$. In addition, we detected that $19 \%$ of our isolates carried aac $C 2$, while Akers et al. reported a $3.7 \%$ proportion of this gene ${ }^{25}$, and another Iranian study detected a proportion of $8.04 \%$ for this gene owing to which all isolates were non-susceptible to kanamycin ${ }^{5}$. However, $89.4 \%$ of our isolates containing this gene showed an MIC range of $\geq 256 \mu \mathrm{g} / \mathrm{mL}$ for spectinomycin, streptomycin, kanamycin, and tobramycin, while $100 \%$ of them exhibited this MIC range for gentamicin. Moreover, according to research by Hasani et al., this gene was detected in SG1$4^{1}$, while Nowak et al. did not detect this gene among their isolates ${ }^{28}$.

Additionally, the $\operatorname{arm} A$ gene, which is an effective factor in the development of resistance to aminoglycosides in $A$. baumannii, can be placed on plasmids and frequently recognized in carbapenem-resistant isolates ${ }^{18}$. This gene encodes a 16S rRNA methylase, resulting in limited access of aminoglycosides to the ribosome of the bacteria and causing high-level aminoglycoside resistance (HLAR) against gentamicin, tobramycin, amikacin, and kanamycin ${ }^{1}$. Surprisingly, among 22 arm $A$-positive $A$. baumannii isolates in this study, $21(95.4 \%), 16(72.7 \%), 18(81.8 \%)$, and 21 $(95.4 \%)$ isolates showed high-level resistance (MIC $\geq 256 \mu \mathrm{g} / \mathrm{mL})$ to gentamicin, tobramycin, amikacin, and kanamycin, respectively, with an $\mathrm{MIC}_{50} \geq 128 \mu \mathrm{g} / \mathrm{mL}$. Considering that most isolates in the present study were MDR, and a high proportion of strains harboring the AME genes was detected, the simultaneous presence of carbapenem-resistance genes and AME genes in A. baumannii has been proven ${ }^{18,28}$; this assumption may also be true for our isolates. However, $75-97 \%$ of our isolates were resistant to carbapenems and other $\beta$-lactams. Other studies from South Korea, Iran, and North America have reported armA production by $A$. baumannii $i^{1,27,29}$. Additionally, other researchers have revealed the role of the arm $A$ gene in high-level resistance to amikacin and gentamicin ${ }^{22,30}$.

In addition to the material presented, the most important problem observed in our study was the simultaneous presence of aminoglycoside resistance genes. We detected 22 gene profiles, while Nowak et al. detected only 3 combinations of AME genes from 61 carbapenem-resistant and aminoglycoside non-susceptible A. baumannii isolates ${ }^{28}$. Our most prevalent combinations were $A P H\left(3^{\prime}\right)-V I a+A N T\left(2^{\prime \prime}\right)-I a$ (39 isolates) with $95-100 \%$ resistance rates against aminoglycosides and $A A C(3)-I I a+A A C\left(6^{\prime}\right)$ $I b+A N T\left(3^{\prime \prime}\right)-I a+A P H\left(3^{\prime}\right)-V I a+A N T\left(2^{\prime \prime}\right)-I a$ (14 isolates) of which 93-100\% were resistant to aminoglycosides. The common point between our study and the study by Nowak et al. was the presence of aphA6 among most of the isolates. However, Akers et al. detected 16 AME gene profiles, of which $12(75 \%)$ isolates had a combination of these genes ${ }^{25}$. The most prevalent (38/107 isolates) combination of their study included $A P H\left(3^{\prime}\right)-I a+A N T\left(2^{\prime \prime}\right)-I a$, and 35 $(92.1 \%)$ were concurrently resistant to gentamicin, tobramycin, and 
amikacin. Nevertheless, $85 \%$ of our $A$. baumannii isolates carried more than one AME gene, of which 52 (61.1\%) contained 2 AME genes concurrently and most of them were resistant to all tested aminoglycosides. Moreover, we found that as the number of AME genes increased, the likelihood of resistance to aminoglycosides, especially gentamicin, tobramycin, streptomycin, and kanamycin, increased. Due to the higher proportion of strains harboring the AME genes, especially aph, it may be better to use phosphotransferases and acetyltransferase inhibitors such as the bovine antimicrobial peptide indolicidin, as previously reported ${ }^{31}$, in combination with aminoglycosides in our region, Iran.

\section{CONCLUSIONS}

High-level aminoglycoside MIC ranges in isolates with the simultaneous presence of AME and ArmA-encoding genes indicated the importance of these genes in resistance to aminoglycosides in A. baumannii. However, it seems that the selection of the appropriate antibiotic based on antimicrobial susceptibility testing and the use of combination therapy would be effective in overcoming this problem in such countries. Therefore, it is necessary to collect data from monitoring studies for the prevention, treatment, and control of the infections caused by this microorganism.

\section{ACKNOWLEDGMENTS}

We thank the laboratory staff of the hospitals for helping in the collection of the clinical isolates.

\section{ETHICAL APPROVAL STATEMENT}

This study was conducted in accordance with the Declaration of Helsinki; however, written informed consent was obtained from the patients or a close family member before hospitalization, and the classifying information of each sample was kept secret. This study was approved by the Iran National Committee for Ethics in Biomedical Research with the National Ethical Code (consent ref number) IR.MAZUMS.REC.1398.074.

\section{FINANCIAL SUPPORT}

This study is a report of a database from MSc. thesis registered and carried out in Molecular and Cell Biology Research Center of Mazandaran University of Medical Sciences in Sari, Iran. (Grant No. 1479).

\section{AUTHORS' CONTRIBUTION}

MAJ: Acquisition of data, Analysis and interpretation of data, Drafting of manuscript; MA: Literature search, Analysis and interpretation of data, Review and final approval of the article; BM: Literature search, Analysis and interpretation of data, Review and final approval of the article; HRG: Study concept and design, Literature search, Acquisition of data, Review and final approval of the article.

\section{REFERENCES}

1. Hasani A, Sheikhalizadeh V, Ahangarzadeh Rezaee M, RahmatiYamchi M, Hasani A, Ghotaslou R, et al. Frequency of AminoglycosideModifying Enzymes and ArmA Among Different Sequence Groups of Acinetobacter baumannii in Iran. Microb Drug Resist. 2016;22(5):347-53.
2. Manchanda V, Sanchaita S, Singh N. Multidrug resistant Acinetobacter. J Glob Infect Dis. 2010;2(3):291.

3. Bergogne-Berezin E, Towner K. Acinetobacter spp. as nosocomial pathogens: microbiological, clinical, and epidemiological features. Clin Microbiol Rev. 1996;9(2):148.

4. Ayats J, Corbella X, Ardanuy C, Dominguez M, Ricart A, Ariza J, et al. Epidemiological significance of cutaneous, pharyngeal, and digestive tract colonization by multiresistant Acinetobacter baumannii in ICU patients. J Hospital Infect. 1997;37(4):287-95.

5. Sheikhalizadeh V, Hasani A, Ahangarzadeh Rezaee M, RahmatiYamchi M, Hasani A, Ghotaslou R, et al. Comprehensive study to investigate the role of various aminoglycoside resistance mechanisms in clinical isolates of Acinetobacter baumannii. J Infect Chemother. 2017;23(2):74-9.

6. Fournier PE, Richet H, Weinstein RA. The epidemiology and control of Acinetobacter baumannii in health care facilities. Clin Infect Dis. 2006;42(5):692-9.

7. Huang LY, Chen TL, Lu PL, Tsai CA, Cho WL, Chang FY, et al. Dissemination of multidrug-resistant, class 1 integron-carrying Acinetobacter baumannii isolates in Taiwan. Clin Microbiol Infect. 2008;14(11):1010-9.

8. Poirel L, Nordmann P. Carbapenem resistance in Acinetobacter baumannii: mechanisms and epidemiology. Clin Microbiol Infect. 2006;12(9):826-36.

9. Song W, Lee KM, Kang HJ, Shin DH, Kim DK. Microbiologic aspects of predominant bacteria isolated from the burn patients in Korea. Burns. 2001;27(2):136-9.

10. Taylor G, Kibsey P, Kirkland T, Burroughs E, Tredget E. Predominance of staphylococcal organisms in infections occurring in a burns intensive care unit. Burns. 1992;18(4):332-5.

11. Nemec A, Dolzani L, Brisse S, van den Broek P, Dijkshoorn L. Diversity of aminoglycoside-resistance genes and their association with class 1 integrons among strains of pan-European Acinetobacter baumannii clones. J Med Microbiol. 2004;53(12):1233-40.

12. Ramirez MS, Tolmasky ME. Aminoglycoside modifying enzymes. Drug. Resist. Updates. 2010;13(6):151-71.

13. Shaw K, Rather P, Hare R, Miller G. Molecular genetics of aminoglycoside resistance genes and familial relationships of the aminoglycosidemodifying enzymes. Microb Mol Biol Rev. 1993;57(1):138-63.

14. Miller G. The most frequently occurring aminoglycoside resistance mechanisms-combined results of surveys in eight regions of the world. J Chemother. 1999;7(2):17-30.

15. Vetting MW, de Carvalho LPS, Yu M, Hegde SS, Magnet S, Roderick $\mathrm{SL}$, et al. Structure and functions of the GNAT superfamily of acetyltransferases. Arch Biochem Biophys. 2005;433(1):212-26.

16. Wright GD, Thompson PR. Aminoglycoside phosphotransferases: proteins, structure, and mechanism. Front Biosci. 1999;4:9-21.

17. Nemec A, Dijkshoorn L, van der Reijden TJ. Long-term predominance of two pan-European clones among multi-resistant Acinetobacter baumannii strains in the Czech Republic. J Med Microbiol. 2004;53(2):147-53.

18. Doi Y, Wachino JI, Arakawa Y. Aminoglycoside resistance: the emergence of acquired 16S ribosomal RNA methyltransferases. Infect Dis Clin. 2016;30(2):523-37.

19. Turton JF, Gabriel S, Valderrey C, Kaufmann ME, Pitt TL. Use of sequence-based typing and multiplex PCR to identify clonal lineages of outbreak strains of Acinetobacter baumannii. Clin Microbiol Infect. 2007;13(8):807-15. 
20. Turton JF, Woodford N, Glover J, Yarde S, Kaufmann ME, Pitt TL. Identification of Acinetobacter baumannii by detection of the blaOXA51-like carbapenemase gene intrinsic to this species. J Clin Microbiol. 2006;44(8):2974-6.

21. Wayne PA. In C. Performance standards for antimicrobial susceptibility testing: Clinical and Laboratory Standards Institute (CLSI). 2018.

22. Cho YJ, Moon DC, Jin JS, Choi CH, Lee YC, Lee JC. Genetic basis of resistance to aminoglycosides in Acinetobacter spp. and spread of arm A in Acinetobacter baumannii sequence group 1 in Korean hospitals. Diagn Microbiol Infect Dis. 2009;64(2):185-90.

23. Bimboim H, Doly J. A rapid alkaline extraction procedure for screening recombinant plasmid DNA. Nucleic Acids Res. 1979;7(6):1513-23.

24. Lari AR, Azimi L, Rahbar M, Fallah F, Alaghehbandan R. Phenotypic detection of Klebsiella pneumoniae carbapenemase among burns patients: first report from Iran. Burns. 2013;39(1):174-6.

25. Akers KS, Chaney C, Barsoumian A, Beckius M, Zera W, Yu X, et al. Aminoglycoside Resistance and Susceptibility Testing Errors in Acinetobacter baumannii-calcoaceticus Complex. J Clin Microbiol. 2010;48(4):1132-8.

26. Goli HR, Nahaei MR, Ahangarzadeh Rezaee M, Hasani A, Samadi Kafil H, Aghazadeh M, et al. Prevalence and molecular characterization of Class 1 integrons among clinical isolates of Pseudomonas aeruginosa in Northwest of Iran. Mol Genet Microbiol Virol. 2017;32(2):109-15.

27. Lee H, Yong D, Yum JH, Roh KH, Lee K, Yamane K, et al. Dissemination of 16S rRNA methylase-mediated highly amikacin-resistant isolates of Klebsiella pneumoniae and Acinetobacter baumannii in Korea. Diagn Microbiol Infect Dis. 2006;56(3):305-12.

28. Nowak P, Paluchowska PM, Budak A. Co-occurrence of carbapenem and aminoglycoside resistance genes among multidrug-resistant clinical isolates of Acinetobacter baumannii from Cracow, Poland Med Sci Monit Basic Res. 2014;20:9-14.

29. Doi Y, Adams JM, Yamane K, Paterson DL. Identification of 16S rRNA methylase-producing Acinetobacter baumannii clinical strains in North America. Antimicrob Agents Chemother. 2007;51(11):4209-10.

30. Sung JY, Kwon KC, Cho HH, Koo SH. Antimicrobial resistance determinants in imipenem-nonsusceptible Acinetobacter calcoaceticusbaumannii complex isolated in Daejeon, Korea. Korean J Lab Med. 2011;31(4):265-70.

31. Boehr DD, Draker KA, Koteva K, Bains M, Hancock RE, Wright GD. Broad-spectrum peptide inhibitors of aminoglycoside antibiotic resistance enzymes. Chem Biol. 2003;10(2):189-96. 